\title{
CARACTERÍSTICAS DA EVASÃO DOS ESTUDANTES DO PROJETO PILOTO DO CURSO DE ADMINISTRAÇÃO A DISTÂNCIA DA UFSC
}

\author{
Andressa Sasaki Vasques Pacheco - EGC/UFSC - andressa.ufsc@ gmail.com \\ Pedro Antônio de Melo - CPGA/UFSC - pedromelo@inpeau.ufsc.br \\ Kelly Cristina Benetti Tonani Tosta - EGC/UFSC - kellyadm@ hotmail.com \\ Marina Keiko Nakayama - EGC/UFSC - marina@egc.ufsc.br \\ Maurício Rissi - CPGA/UFSC - mauriciorissiadm@ gmail.com \\ Patrícia de Sá Freire - EGC/UFSC - patriciasafreire@terra.com.br \\ Aline Pereira Soares - EGC/UFSC -
}

\section{RESUMO}

Esta pesquisa tem como objetivo de analisar as características da evasão dos estudantes do projeto piloto do curso de Administração a distância da UFSC do primeiro semestre. Quanto ao tipo de estudo, caracteriza-se como teórico-empírico, descritivo, ex-post-facto, aplicado, bibliográfica, estudo de caso e quantitativa. Desta forma, várias análises foram feitas em relação a evasão do curso, podendo constatar que a maioria dos resultados corrobora com o estado da arte sobre evasão da educação a distancia, como por exemplo a maior evasão no começo do curso, dos alunos com desempenho menor, etc. Por meio de uma monitoração constante é possível conhecer e prevenir a evasão nos cursos. Para que as informações advindas dessas pesquisas sejam utilizadas efetivamente, enfatiza-se a necessidade de uma estrutura adequada para a equipe de gestão do curso.

\section{Palavras-chaves: Evasão. Administração. Educação a distância.}

\section{INTRODUÇÃO}

O aumento de informações e TIC, bem como caminhos para o aprendizado tem gerado novas oportunidades de como as pessoas podem aprender e adquirir conhecimentos A autora complementa ainda que várias são as expressões para delimitar essa modalidade de ensino mediada por tecnologias, sendo que este trabalho utilizará a expressão Educação a distância EaD (ANOHINA, 2005).

A Ead é caracterizada por: separação entre professor e estudante, a autonomia do estudante, o uso de tecnologias para compartilhamento de material e comunicação de mão dupla entre os agentes (PAULSEN, 2002).

O desenvolvimento da modalidade a distância nos últimos anos serviu para implementar os projetos educacionais mais diversos em distintas e complexas situações. As múltiplas possibilidades oferecidas pela educação a distância estão diretamente relacionadas à flexibilidade que caracteriza todos os programas (LITWIN, 2001).

A evasão universitária tem se caracterizado como uma realidade recorrente no âmbito do ensino de graduação, em várias partes do mundo. As formas de acesso e permanência dos alunos nos cursos superiores, especificamente a nível da graduação, têm preocupado pesquisadores e gestores no mundo inteiro (FARIA, ALCANTARA, GOIA, 2008).

Para enfrentar esses desafios, o conjunto das instituições participantes do Fórum das Estatais da Educação propôs a criação do Sistema Universidade Aberta do Brasil (UAB), que congrega instituições públicas de educação superior para ofertar cursos e programas da modalidade a distância, tendo como ponto de partida a consolidação e a diversificação de experiências, em variados níveis de ensino, que vêm gradativamente tomando forma no país (ABRA$\mathrm{EAD}, 2007)$. 
A Universidade Federal de Santa Catarina (UFSC) é uma das instituições que aderiram a essa parceria. Com uma experiência nacionalmente reconhecida e responsável por $52 \%$ da publicação nacional sobre EaD (ABRAEAD, 2007) a UFSC tem ampliado o contingente de estudantes por meio do ensino a distância.

Um dos projetos inserido nessa ampliação do ensino, é o projeto piloto em Administração. Este projeto está presente em mais de 20 estados brasileiros e é resultado de uma parceria entre a UAB - Universidade Aberta do Brasil (projeto pertencente ao Ministério da Educação - MEC) e Banco do Brasil.

Em Santa Catarina, este curso teve início em julho de 2006, e é destinado aos funcionários do Banco do Brasil, servidores da UFSC e outros servidores públicos da esfera federal, estadual e municipal. O curso iniciou suas atividades com 654 alunos, em dez pólos espraiados pelo Estado de Santa Catarina: Araranguá, Canoinhas, Chapecó, Criciúma, Florianópolis, Joinville, Lages, Laguna, Palhoça e Tubarão.

Nesse sentido, esta pesquisa tem como objetivo de analisar as características da evasão dos estudantes do primeiro semestre do projeto piloto do curso de Administração a distância da UFSC.

\section{EVASÃO NA EDUCAÇÃO A DISTÂNCIA}

Inicialmente, resgata-se os conceitos norteadores dessa pesquisa quanto evasão e EaD. A evasão definitiva é a saída definitiva da universidade, ou seja, é aquela pela qual o aluno se afasta da instituição, por abandono, desistência definitiva do curso ou transferência para outra universidade. Já educação a distância é a educação formal, baseada em uma instituição na qual o grupo de aprendizagem se separa e na qual se utilizam sistemas de telecomunicações interativos para conectar estudantes, recursos e instrutores (SIMONSON, 2006).

Em complemento considera-se evasão a desistência do curso, incluindo os que, após terem se matriculado, nunca se apresentaram ou se manifestaram de alguma forma para os colegas e mediadores do curso, em qualquer momento (FÁ VERO; FRANCO, 2006). Outro conceito é apresentado por Maia e Meirelles (2005), para os quais a evasão dos cursos consiste em estudantes que não completam cursos ou programas de estudo, podendo ser considerado como evasão aqueles alunos que se matriculam e desistem antes mesmo de iniciar o curso.

Na modalidade a distância, conforme Rumble (2003), em geral, as taxas de conclusão são bastantes fracas e os índices de evasão altos, mas a comparação entre os índices das IES é prejudicado pelos diferentes cálculos aplicados. Para algumas IES, são contabilizados como alunos regulares somente aqueles que após a matrícula freqüentam pelo menos dois meses de curso, ou seja, os alunos que apenas se matriculam e os que só participam das aulas por um período inferior a esse não são inclusos como alunos dessa IES, não sendo contabilizados assim como alunos evadidos da mesma. Como exemplo pode-se citar a British Open University, a qual elimina aqueles que não seguem o curso regularmente e só matriculam novos alunos após dois ou três meses de freqüência.

Aretio (1987) corrobora com esta visão, afirmando que muitos simplesmente se matriculam sem chegar a realmente participar do curso. Por isso, algumas instituições só contabilizam os alunos que se apresentam aos exames. Estes índices, comparados com os da universidade convencional, são mais aproximados e mais reais.

Complementa ainda que nas instituições a distância, muitos dos alunos se matricula, adquirem o material didático obrigatório e nada mais se volta a saber deles. Estes alunos abandonam o curso sem ter provado sua capacidade ou o alcance de sua possível dedicação ao estudo, ao menos sem que isso conste. Um aviso para a detecção de um possível aluno a evadir do curso é o não cumprimento de alguma prova ou exame das matérias (ARETIO, 2002). 
Portanto, de acordo com Aretio (2002), tem-se dois tipos de abandonos em EaD: abandono sem começar e abandono real. Fala-se de abandono sem começar quando refere-se a aqueles estudantes dos quais não existe registro avaliador algum mesmo tendo estado matriculados um ou mais anos. Abandono real seria aquele em que os estudantes que chegam a ter um registro de avaliação e depois abandonam sem terminar os estudos. Este tipo de abandono vem sendo mais próximo, em porcentagem, ao dos cursos presenciais.

De acordo com Rumble (2003), a evasão é encarada como um fracasso para as IES, mas salienta que alguns estudantes decidem freqüientar um curso sem a preocupação de cumprir todos os requisitos ou de passar nos exame, fazendo com que se considerar somente índices de conclusão e abandono não sejam uma boa medida para avaliar o sucesso individual dos estudantes.

Essa afirmação é rebatida pela UNESCO (1997), ao se tratar dos custos da IES, ao afirmar que um elemento muito relevante na comparação de custos é o índice de formandos ou taxa de estudantes que completam os estudos. Destaca ainda que muitos estudos de custos deixam de levar em consideração este detalhe, tanto na educação convencional como na aprendizagem aberta e a distância.

Resgata-se essa discussão por considerar a evasão não somente como um problema de custo de uma IES, mas também como um problema social. Os aspectos qualitativos da aprendizagem e da aquisição de novos conhecimentos e habilidades são intangíveis, fazendo com que as perdas advindas da evasão para as IES e para a sociedade sejam imensuráveis.

Quanto à análise de algumas pesquisas em $\mathrm{EaD}$, inicia-se a apresentação desses dados por em estudo desenvolvido por Woodley e Mclntosh (apud ARETIO, 1987), os quais objetivaram levantar os motivos para a não realização da matrícula definitiva (depois do $1^{\circ}$ ano) nos cursos que estavam interessados . Dentre os motivos apontados, $77 \%$ estavam relacionados a problemas de caráter familiar e situações de trabalho; $21 \%$ referiram-se a problemas causados pela forma e o conteúdo dos cursos e $2 \%$ por motivos de caráter administrativo.

Outra pesquisa sobre evasão em EaD remete as seguintes causas de abandono: $61 \%$ em função de problemas de caráter laboral e familiar; $27 \%$ por problemas relacionados ao próprio curso e $12 \%$ por questões de motivação (PHYNTHIAN; CLEMENTS, apud PRETI, 2005).

Já o estudo realizado por Tannous e Ropoli (2005) em cursos de extensão da Unicamp (Universidade Estadual de Campinas), apresentou os seguintes índices de evasão: o primeiro curso oferecido contou com a participação de doze inscritos, dos quais cinco desistiram (índice de evasão $=41,7 \%$ ), o segundo curso estiveram presentes onze inscritos, dos quais seis desistiram (índice de evasão $=54,5 \%$ ), o terceiro curso houve oito inscritos, dos quais quatro desistiram (índice de evasão $=50 \%$ ).

Pierrakeas et al (2004) apresenta um estudo sobre a evasão nos cursos a distância na Grécia. Eles analisaram fatores intrínsecos e extrínsecos as instituições de dois cursos, um com alta evasão e outro com baixa. Concluíram que as causas são semelhantes.

Morgan e Mckenzie (2003) defendem em seu estudo uma maior autonomia dos alunos. Ressaltam que todos tem problemas, não só os alunos, e que estes precisam ser autônomos e independentes para resolver o que for necessários, ou seja, que sejam pró-ativos e não dependam sempre de tutores ou professores.

Complementa-se ainda com a pesquisa de Rovai (2002) o qual argumenta que os cursos a distância precisam criar mais senso de comunidade entre os alunos, a fim de minimizar problemas e o sentimento de solidão deste estudante.

Já Filkins, Kehoe e Mclaughlin, (2001) relatam sete princípios de práticas para EaD: encorajar o contato entre estudantes e a instituição, desenvolver reciprocidade e cooperação entre estudantes, utilizar ativamente técnicas de aprendizado, dar feedback aos alunos, enfati- 
zar trabalhos em equipe, comunicar as expectativas, respeitar os diferentes talentos e formas de aprendizagem.

Quanto ao cenário nacional, a pesquisa do Anuário Brasileiro Estatístico de Educação Aberta e a distância - ABRAEAD - (2007) aponta algumas informações sobre a Evasão em $\mathrm{EaD}$ no Brasil. Quanto aos fatores que influenciaram na evasão destes alunos destacam-se: a falta de tempo e a situação financeira. Outra informação importante aponta que nos cursos de graduação, $96 \%$ da evasão ocorre nos primeiros semestres do curso, o que mostra a importância de pesquisas sobre a evasão dos alunos desde o começo do curso.

Já Fávero e Franco (2006) apresentam uma pesquisa realizada pela FGV-EAESP - Escola de Administração de Empresas de São Paulo da Fundação Getúlio Vargas, em 2005, sobre o índice de evasão em educação superior a distância, alcançando-se os seguintes resultados:

a) os cursos totalmente a distância têm maior evasão (30\%) que os cursos semipresenciais $(8 \%)$;

b) os cursos de extensão e especialização têm $25 \%$ de evasão;

c) enquanto nas públicas ocorre $11 \%$ de evasão, nas privadas o percentual é de $23 \%$;

d) a maior diferença existente está entre os cursos certificados pelo MEC (21\%) e os cursos com certificação própria (62\%). Este percentual de $62 \%$ de evasão em cursos com certificação própria pode indicar que existe pouca credibilidade e confiabilidade nesta certificação, uma vez que, se o certificado for emitido pelo MEC, este índice cai para $21 \%$; e

e) o índice de evasão em cursos totalmente a distância é de $30 \%$.

Outros elementos que não podem deixar de ser analisados são os fatores contribuintes à evasão. Aretio (2002) apresenta alguns desses fatores de acordo com as seguintes categorias: fatores atribuíveis a instituição, circunstâncias sócio-familiares dos alunos e fatores psicopedagógicos.

Aretio (2002) complementa ainda que essa é uma seleção de causas de abandono ou de baixo rendimento. Mas as pesquisas estabeleceram uma ordem de prioridade entre os diferentes fatores conforme se segue: atenção às obrigações laborais; atenção à família; falta de dedicação ao estudo; falta de motivação; equivocada imagem que se tem sobre a instituição e seu nível de exigência; dificuldade de superar as provas presenciais; falta de hábitos, técnicas de estudo e adaptação às tecnologias; falta de preparação prévia; e materiais didáticos deficientes.

Para Maia e Meirelles (2005), um dos fortes fatores que influenciam a evasão é o fato de o curso ser distribuído totalmente a distância, podendo ocasionar que os alunos sintam-se desestimulados a se manterem cursando por não se considerarem integrantes de uma turma. Os autores ressaltam que este é um forte traço cultural; o de encontrar pessoalmente o professor e ter aula presencial. Quando isso ocorre, o aluno se sente como participante de um grupo e mais disposto a interagir a distância, não abandonando o curso.

Outros fatores analisados por Maia e Meirelles (2005), são os Ambientes Virtuais de Ensino e Aprendizagem (AVEA) e a forma de desenho do curso. O desenho do curso relaciona-se à forma como o curso está estruturado considerando a tecnologia computacional, sendo as principais: a videoconferência, a teleconferência, a internet e o CD-ROM. Dessa maneira, destacam que o índice de evasão mantém relação com a tecnologia utilizada no curso a distância.

Corroborando com os autores, Fávero e Franco (2006) ressaltam também a importância de um AVEA interativo, pois os alunos que fazem cursos a distância, na sua grande maioria, tem uma característica em comum, que é a solidão, isto é, uma sensação de abandono que os cercam durante todo o curso, principalmente quando não ocorre uma maior interação entre os atores deste processo.

V. $7 \mathrm{~N}^{\mathrm{o}}$ 3, dezembro, 2009 
Em continuidade, Maia e Meirelles (2005) destacam que o índice de evasão pode ser justificado também por variáveis exógenas ao curso a distância, como questões particulares dos alunos.

Em complemento sobre os fatores de evasão na modalidade a distância, destaca-se que se for considerado que a maioria dos estudantes é formada por adultos entre 25 e 40 anos, que trabalham e estudam, percebe-se que uma das grandes causas da evasão é o cansaço que as pessoas sentem ao final do dia, impossibilitando-as de aprender na sua totalidade, independente do local onde esteja ocorrendo a aula. (FÁVERO; FRANCO, 2006).

Também cabe destacar que muitos alunos se surpreendem com a consistência dos cursos, pois há uma sensação, geralmente frustrada, que os cursos a distância são mais fáceis que os presenciais (ABRAEAD, 2007).

Em relação às ações para minimizar a evasão em EaD, Rumble (2003) cita alguns itens, como: fornecimento de excelente material pedagógico; prestação de informações rápidas e corretas aos estudantes, para evitar que um aluno escolha incorretamente o curso que deseja seguir ou para o qual não esteja ainda preparado; informação rápida aos estudantes e assistências àqueles que já estão no sistema, ajudando-os a superar problemas nos estudos; e criação de um clima estimulante para que os alunos busquem orientação junto aos tutores, conselheiros e mesmo com outro estudantes. Enfim, trata-se de preparar um ambiente que estimule a participação em um grupo de estudos, de forma a incentivar a motivação e o interesse.

\section{PROCEDIMENTOS METODOLÓGICOS}

Quanto ao tipo de estudo, caracteriza-se como teórico-empírico, descritivo, ex-postfacto, aplicado, bibliográfica e estudo de caso. Em relação à abordagem desta pesquisa, classifica-se como predominante quantitativa.

Os principais dados secundários coletados dizem respeito a fatores de evasão no ensino superior, características de cursos a distância, índices de evasão em diversos cursos.

Foram analisados os dados dos 110 alunos evadidos do curso, por meio de questionários aplicados com os alunos quando estes fizeram o vestibular do curso.

Além disso, utilizou-se também pesquisas com os alunos freqüentes sobre o desempenho dos tutores do curso, realizadas ao fim de cada disciplina do primeiro semestre.

Os dados foram analisados estatisticamente por meio de medidas descritivas como freqüências e médias.

Outro método estatístico utilizado foi a correlação. Conforme Barbetta (2005), o conceito de correlação refere-se a uma associação numérica entre duas variáveis, não implicando, necessariamente, uma relação de causa-e-efeito, ou mesmo em uma estrutura com interesses práticos. Duas variáveis X e Y, estão correlacionadas positivamente quando caminham num mesmo sentido, ou seja, elementos com valores pequenos de $\mathrm{X}$ tendem a ter valores pequenos de $\mathrm{Y}$ e elementos com valores grandes de $\mathrm{X}$ tendem a ter valores grande de $\mathrm{Y}$.

A análise de dados para verificar correlações é usualmente feita em termos exploratórios, onde a verificação de uma correlação serve como um elemento auxiliar na análise do problema em estudo. Ou seja, o estudo da correlação numérica entre as observações de duas variáveis é geralmente um passo intermediário na análise de um problema. Para este trabalho, foi feita a correlação entre o índice de evasão por tutor e a avaliação dos tutores feita pelos próprios alunos.

\section{CARACTERÍSTICAS DA EVASÃO NO CURSO}


Este capítulo aborda informações relativas à evasão nesse curso, como gênero e categoria funcional, evasão por pólo e por desempenho de tutores, bem como período que ocorreu a evasão no curso.

Iniciando-se essas análises, $20 \%$ dos evadidos somente efetuaram a matrícula no curso, não cursando nenhuma das disciplinas, este dado vem corroborar com o estado da arte, que indica que muitos alunos só efetuam a matrícula e não participam do curso. Em algumas pesquisas, esses estudantes não são considerados evadidos, pois não participaram ativamente do curso. Por este ser um projeto piloto, responsável por gerar informações para futuros cursos, foram considerados também como população alvo os alunos que somente efetuaram sua matrícula.

Quanto ao desempenho dos alunos evadidos, resgata-se as informações de Souza (1999) que apresenta que os alunos evadidos têm desempenho menor do que os alunos freqüentes. Na primeira disciplina (Introdução a Educação a Distância), 40,90\% dos alunos evadidos reprovaram. Já na segunda disciplina (Administração - Introdução e Teorias), 99\% dos alunos evadidos reprovaram.

Somente 20,9\% desses alunos evadidos começaram a terceira disciplina (Ciência Política), sendo que todos reprovaram. Na última disciplina do módulo (Sociologia), este índice caiu para $13,63 \%$, sendo que novamente todos os alunos evadidos reprovaram nesta matéria. Esses dados corroboram com as pesquisas empíricas analisadas, as quais destacam que a evasão dos alunos tende a acontecer mais expressivamente nas primeiras disciplinas, além de resultados negativos constantes virem a desmotivar o aluno, contribuindo ao seu abandono do curso.

Dando continuidade à análise das características da evasão no curso de Administração a distância da UFSC, apresenta-se informações relativas a categoria funcional dos alunos em geral e dos evadidos.

Tabela 1: categoria funcional dos alunos evadidos

\begin{tabular}{lrrrr}
\hline & \multicolumn{2}{c}{ Alunos que iniciaram o curso } & \multicolumn{2}{c}{ Alunos Evadidos } \\
\hline & Freq. Absoluta & Freq. Relativa & Freq. Absoluta & $\begin{array}{c}\text { Freq. Rela- } \\
\text { tiva }\end{array}$ \\
\hline Funcionários do Banco do Brasil & & & 53 & $48,18 \%$ \\
Servidores Públicos da UFSC & 350 & $53,52 \%$ & 12 & $10,91 \%$ \\
Servidores Públicos em SC & 65 & $9,94 \%$ & 45 & $40,91 \%$ \\
Total & 239 & $36,54 \%$ & 110 & $100,00 \%$ \\
\hline
\end{tabular}

Fonte: dados primários

Tabela 2: evasão por categoria funcional

\begin{tabular}{lr}
\hline \multicolumn{1}{c}{ Categoria funcional } & Evasão (\%) \\
\hline Funcionários do Banco do Brasil & $15,14 \%$ \\
Servidores Públicos da UFSC & $18,46 \%$ \\
Servidores Públicos em SC & $18,83 \%$ \\
\hline
\end{tabular}

Fonte: dados primários

Em se tratando da categoria funcional dos alunos evadidos, pôde-se perceber um percentual de 18,46\% para funcionários da UFSC, 18,83\% para outros servidores públicos em Santa Catarina e 15,14\% do Banco do Brasil. Ressalta-se que, como já descrito, a UFSC promoveu uma rematrícula para os alunos que haviam evadido no primeiro semestre, sendo que o Banco do Brasil atuou ativamente nesse processo a fim de que seus funcionários que não estivessem freqüientando o curso voltassem a fazê-lo, acarretando assim nesses percentuais menores de evasão para esta categoria funcional.

A próxima categoria a ser analisada diz respeito ao gênero dos alunos evadidos.

V. $7 \mathrm{~N}^{\circ} 3$, dezembro, 2009 
Tabela 3: gênero dos alunos evadidos

\begin{tabular}{lrrrr}
\hline & \multicolumn{2}{c}{ Alunos que iniciaram o curso } & \multicolumn{2}{c}{ Alunos evadidos } \\
\hline & Freq. Absoluta & Freq. Relativa & Freq. Absoluta & $\begin{array}{c}\text { Freq. Relati- } \\
\text { va }\end{array}$ \\
\hline Feminino & 196 & $30,96 \%$ & 38 & $34,55 \%$ \\
Masculino & 437 & $69,04 \%$ & 72 & $65,45 \%$ \\
\hline Total & 633 & $100,00 \%$ & 110 & $100,00 \%$ \\
\hline
\end{tabular}

Fonte: dados primários

Tabela 4: evasão por gênero

\begin{tabular}{lr}
\hline \multicolumn{1}{c}{ Gênero } & Evasão \\
\hline Feminino & $19,39 \%$ \\
Masculino & $16,48 \%$ \\
\hline Fonte: dados primários &
\end{tabular}

Quanto à análise da evasão por gênero, percebe-se uma maior concentração no gênero feminino, com 19,39\%, enquanto o masculino teve percentuais de 16,48\%. Esses dados corroboram com a pesquisa realizada por Aretio (1987), que indica uma maior evasão das mulheres em relação aos homens.

Buscou-se também informações relativas à idade dos estudantes, o tempo que concluiu o ensino médio e a sua nota final do vestibular.

Tabela 5: Análise dos alunos geral e evadidos

\begin{tabular}{lrrrrrr}
\hline & \multicolumn{3}{c}{$\begin{array}{c}\text { Alunos que iniciaram o } \\
\text { curso }\end{array}$} & \multicolumn{3}{c}{ Alunos evadidos } \\
\hline & Mínimo & Máximo & Média & Mínimo & Máximo & Média \\
\hline IDADE & 21 & 60 & 36 & 21 & 53 & 37 \\
Tempo de Conclusão do Ensino Médio & 2 & 40 & 17 & 3 & 35 & 17 \\
Nota Final do vestibular & 14 & 37 & 27 & 14 & 37 & 27 \\
\hline
\end{tabular}

Fonte: dados primários

Analisando os itens das tabelas 5, pôde-se constatar que quanto à idade dos alunos entrantes do curso e dos evadidos não há uma diferença significativa, obtendo-se valores de média de idade de 37 anos para os alunos evadidos e 36 para os alunos em geral do curso.

Outras análises feitas foram em relação a quanto tempo os alunos haviam concluído o Ensino Médio e qual sua nota no vestibular deste curso. Não houve diferença entre os valores dos alunos evadidos e de todos os alunos entrantes do curso.

É necessário destacar também a idade e o tempo de conclusão do Ensino Médio. Quanto à idade, corroborando com as informações de Aretio (2002) os estudantes a distância são adultos, neste caso, com uma média de 36 anos. Outra informação pertinente é o tempo de conclusão do ensino médio, podendo constar que em média os alunos terminaram essa etapa há 17 anos atrás, podendo com isso gerar dificuldades na sua aprendizagem. Este ponto, ainda que relevante, não pode ser conclusivo, pois alguns alunos deram continuidade aos seus estudos, como as informações apresentadas na escolaridade dos alunos, fazendo com que as dificuldades advindas do longo período de conclusão do ensino médio possam ser minimizadas.

O próximo tópico a ser analisado é a distribuição da evasão pelos pólos de ensino do curso. Antes de iniciarmos, cabe destacar o conceito utilizado para pólo estruturado, sendo que se entende este como: pólo com infra-estrutura adequada (sala de videoconferência, biblioteca, sala de informática), bem como estrutura administrativa de apoio (coordenador de pólo e monitor). 


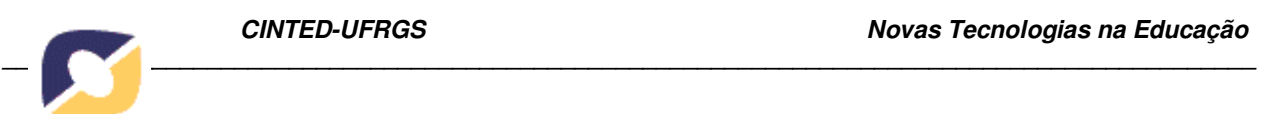

Tabela 6: Evasão por pólo

\begin{tabular}{lccc}
\hline \multicolumn{1}{c}{ Pólo } & Número de alunos & Alunos Evadidos & Freq. Relativa de Evadidos \\
\hline Araranguá & 42 & 7 & $16,67 \%$ \\
Canoinhas & 37 & 8 & $21,62 \%$ \\
Chapecó & 57 & 10 & $17,54 \%$ \\
Criciúma & 42 & 11 & $26,19 \%$ \\
Florianópolis & 198 & 32 & $16,16 \%$ \\
Joinville & 110 & 18 & $16,36 \%$ \\
Lages & 52 & 5 & $9,62 \%$ \\
Laguna & 34 & 4 & $11,76 \%$ \\
Palhoça & 52 & 10 & $19,23 \%$ \\
Tubarão & 30 & 5 & $16,67 \%$ \\
Total & 654 & 110 & $16,82 \%$ \\
\hline Fonte: dados primário
\end{tabular}

Fonte: dados primários

Quanto à análise da evasão por pólo de ensino pôde-se constatar que o pólo com maior índice de evasão foi o de Criciúma (26,19\%). Os pólos de Canoinhas (21,62\%), Palhoça $(19,23 \%)$ e Chapecó $(17,54 \%)$ tiveram índices acima da média, podendo este fato ser causado por não terem o pólo estruturado durante o primeiro semestre do curso. O pólo de Joinville $(16,36 \%)$ também apresentou problemas quanto a sua estrutura, mas não teve índices acima da média. do curso.

Os pólos de Laguna $(11,76 \%)$ e Lages $(9,62 \%)$ tiveram os menores índices de evasão

Os fatores ligados à tutoria devem ter atenção especial, pois em muitos cursos a evasão está estreitamente ligada com o desempenho dos tutores (ARETIO, 2002; RUMBLE, 2003).

Com isso, foi realizada uma análise comparativa entre o desempenho dos tutores, por meio de avaliação de desempenho respondida pelos alunos do curso, e o número de alunos evadidos por tutor. Essa avaliação de desempenho foi realizada com os alunos após a primeira disciplina do curso e após a última disciplina do primeiro módulo, por meio de um questionário.

Tabela 7: Evasão e desempenho dos tutores

\begin{tabular}{lcccc}
\hline & $\begin{array}{c}\text { Alunos eva- } \\
\text { didos }\end{array}$ & $\begin{array}{c}\text { Desempenho } \\
\text { inicial }\end{array}$ & $\begin{array}{c}\text { Desempenho } \\
\text { Final }\end{array}$ & $\begin{array}{c}\text { Média do De- } \\
\text { sempenho }\end{array}$ \\
\hline Tutor 1 & 5 & 9,00 & 9,57 & 9,29 \\
Tutor 2 & 2 & 8,97 & 9,50 & 9,23 \\
Tutor 3 & 2 & 8,72 & 9,36 & 9,04 \\
Tutor 4 & 6 & 8,28 & 9,17 & 8,72 \\
Tutor 5 & 1 & 8,78 & 9,00 & 8,89 \\
Tutor 6 & 4 & 8,83 & 8,82 & 8,83 \\
Tutor 7 & 5 & 8,49 & 8,57 & 8,53 \\
Tutor 8 & 5 & 8,54 & 8,52 & 8,53 \\
Tutor 9 & 7 & 8,85 & 8,50 & 8,68 \\
Tutor 10 & 10 & 8,04 & 8,50 & 8,27 \\
Tutor 11 & 8 & 8,01 & 8,50 & 8,26 \\
Tutor 12 & 2 & 8,41 & 8,44 & 8,43 \\
Tutor 13 & 5 & 8,94 & 8,43 & 8,68 \\
Tutor 14 & 6 & 8,70 & 8,38 & 8,54 \\
Tutor 15 & 2 & 8,33 & 8,36 & 8,35 \\
Tutor 16 & 5 & 7,61 & 8,31 & 7,96 \\
Tutor 17 & 3 & 8,73 & 8,29 & 8,51
\end{tabular}

V. $7 \mathrm{~N}^{\mathrm{o}}$ 3, dezembro, 2009 


\begin{tabular}{lllll}
\cline { 3 - 4 } & \multicolumn{2}{l}{ CINTED-UFRGS } & Novas Tecnologia \\
\cline { 3 - 5 } & & & & \\
Tutor 18 & 4 & 8,32 & 8,25 & 8,28 \\
Tutor 19 & 5 & 8,75 & 8,00 & 8,38 \\
Tutor 20 & 5 & 8,42 & 7,86 & 8,14 \\
Tutor 21 & 4 & 7,90 & 7,85 & 7,88 \\
Tutor 22 & 6 & 8,60 & 7,50 & 8,05 \\
Tutor 23 & 4 & 7,78 & 7,50 & 7,64 \\
Tutor 24 & 4 & 7,69 & 6,22 & 6,95 \\
\hline Fonte: & & & &
\end{tabular}

Fonte: dados primários

Tabela 8: Correlação entre alunos evadidos e desempenho dos tutores

\begin{tabular}{lrrr}
\hline & Alunos evadidos & Desempenho tutor inicial & Desempenho tutor final \\
\hline Alunos evadidos & 1 & $-0,223$ & $-0,125$ \\
Desempenho tutor inicial & $-0,223$ & 1 & \\
Desempenho tutor final & $-0,125$ & 0,591 & 1 \\
\hline
\end{tabular}

Fonte: dados primários

A média de evasão por tutor foi de 4,58 alunos, e o desempenho médio dos mesmos foi de 8,44 inicialmente, e 8,39 ao final do primeiro módulo.

Mesmo apresentando índices não conclusivos, com a correlação em torno de - 0,2, percebe-se que o resultado (negativo) apresenta uma tendência de que há uma ligação inversa entre os fatores, ou seja, quanto maior o desempenho do tutor, menor será seu índice de alunos evadidos.

Com isso, ressalta-se a importância de um sistema de acompanhamento (tutoria) adequado e supervisionado. Além disso, recomenda-se a avaliação periódica desse sistema, como por exemplo por meio de uma avaliação de desempenho dos tutores.

\section{CONSIDERAÇÕES FINAIS}

Os projetos pilotos são experiências para futuros cursos, devendo assim ser fonte de informação e pesquisas. Uma das preocupações dos gestores das IES é o índice de evasão dos alunos dessas instituições, devendo monitorar também este fato em projetos pilotos.

Em busca de informações para uma das IES participante do projeto piloto da U$\mathrm{AB} / \mathrm{MEC}$, este trabalho objetivou analisar as características da evasão dos estudantes do projeto piloto do curso de Administração a distância da UFSC do primeiro semestre.

Iniciando-se essas análises, $20 \%$ dos evadidos somente efetuaram a matrícula no curso, não cursando nenhuma das disciplinas, este dado vem corroborar com o estado da arte, que indica que muitos alunos só efetuam a matrícula e não participam do curso. Esses dados corroboram com as pesquisas empíricas analisadas, as quais destacam que a evasão dos alunos tende a acontecer mais expressivamente nas primeiras disciplinas, além de resultados negativos constantes virem a desmotivar o aluno, contribuindo ao seu abandono do curso.

Em se tratando da categoria funcional dos alunos evadidos, pôde-se perceber um percentual de 18,46\% para funcionários da UFSC, 18,83\% para outros servidores públicos em Santa Catarina e 15,14\% do Banco do Brasil. Quanto à análise da evasão por gênero, percebese uma maior concentração no gênero feminino, com 19,39\%, enquanto o masculino teve percentuais de $16,48 \%$. Pôde-se constatar que quanto à idade dos alunos entrantes do curso e dos evadidos não há uma diferença significativa, obtendo-se valores de média de idade de 37 anos para os alunos evadidos e 36 para os alunos em geral do curso.

Quanto à análise da evasão por pólo de ensino pôde-se constatar que o pólo com maior índice de evasão foi o de Criciúma (26,19\%). Os pólos de Canoinhas (21,62\%), Palhoça $(19,23 \%)$ e Chapecó $(17,54 \%)$ tiveram índices acima da média, podendo este fato ser causado por não terem o pólo estruturado durante o primeiro semestre do curso.

V. $7 \mathrm{~N}^{\mathrm{o}}$ 3, dezembro, 2009 
Mesmo apresentando índices não conclusivos, com a correlação em torno de - 0,2, percebe-se que o resultado (negativo) apresenta uma tendência de que há uma ligação inversa entre os fatores, ou seja, quanto maior o desempenho do tutor, menor será seu índice de alunos evadidos.

Para que as informações advindas dessas pesquisas sejam utilizadas efetivamente, enfatiza-se a necessidade de uma estrutura adequada para a equipe de gestão do curso. Isso implica em apoio institucional e governamental no caso deste projeto.

\section{REFERÊNCIAS}

ABRAEAD - Anuário Brasileiro Estatístico de Educação Aberta e a Distância. 3.ed. São Paulo: Instituto Monitor, 2007.

ANOHINA, A. Analysis of the terminology used in the field of virtual learning. Educational Technology \& Society, 8 , 91-102. (2005).

ARETIO, García Lorenzo. La educación a distancia: de la teoría a la práctica. Barcelona: Ariel, 2002.

. Rendimiento académico y abandono en la educación superior a distancia. Madrid: UNED, 1987.

FARIA, Lilian Maria de Oliveira Faria; ALCANTARA, V. M. ; GOIA, Carla Vasco. Índice e causas de evasão na Modalidade a Distância em Cursos de Graduação: estudo de caso. In: Universidad 2008 - VI Congresso Internacional de educação Superior, 2008, Havana. II taller Internacional, 2008.

FÁVERO, Rute Vera Maria; FRANCO, Sérgio Roberto Kieling. Um estudo sobre a permanência e a evasão na Educação a Distância. 2006. Disponível em < www.cinted.ufrgs.br/renote/dez2006/artigosrenote/25103.pdf> Acesso em mar. 2007. FILKINS, Joseph W.; KEHOE, Laura E.; MCLAUGHLIN, Gerald W. Retention Research: Issues in Comparative Analysis. Annual Meeting of the Association for Institutional Research, Long Beach, CA, June 2001

LITWIN, Edith. Educação a distância: temas para debate de uma nova agenda educativa. Porto Alegre: Artes Medicas, 2001. MAIA, Marta de Campos; MEIRELLES, Fernando de Souza. Tecnologias de informação e comunicação e os índices de evasão nos cursos a distância. 2005. Disponível em < http://www.abed.org.br/congresso2005/por/pdf/181tcc3.pdf> Acesso em fev. 2007. MORGAN, Christopher K.; MCKENZIE, Anthony D. Is Enough Too Much? The dilemma for online distance learner supporters. The International Review of Research in Open and Distance Learning. v.4. n.1. 2003.

PAULSEN, M. F. Online Education Systems: Discussion and Definition of Terms. 2002. Disponível em: (www.nettskolen.com/forskning/Definition\%20of\%20Terms .pdf). Acesso em junho 2008.

PIERRAKEAS, Christos; XENOS, Michalis; PANAGIOTAKOPOULOS, Christos; VERGIDIS, Dimitris. A Comparative Study of Dropout Rates and Causes for Two Different Distance Education Courses. The International Review of Research in Open and Distance Learning, V.5, N.2 (2004), ISSN: 1492-3831

ROVAI, Alfred P. Building Sense of Community at a Distance. The International Review of Research in Open and Distance Learning. v.3. n.1. 2002.

RUMBLE, Greville. A gestão dos sistemas de ensino a distância. Brasília: Universidade de Brasília: Unesco, 2003.

SIMONSON, Michael. In: BARBERÀ, Elena (coord). Educación abierta y a distancia. Barcelona: UOC, 2006. 
TANNOUS, Kátia; ROPOLI, Edilene. Análise dos aspectos motivacionais relacionados à evasão e à aprovação em um curso de extensão. 2005. Disponível em <

http://www.abed.org.br/congresso2005/por/pdf/152tcc5.pdf> Acesso em fev. 2007.

UNESCO. Aprendizagem aberta e a distância: perspectivas e considerações políticas educacionais. Florianópolis: Imprensa Universitária, UFSC, 1997. 